\title{
Evaluation of the Effect of Inhibiting Lipid Oxidation of Natural Plant Sources in a Meat Model System
}

\author{
Sang-Keun Jin, ${ }^{1}$ Gap-Don Kim, ${ }^{2,3}$ and Jin-Yeon Jeong $\mathbb{D D}^{1}$ \\ ${ }^{1}$ Department of Animal Resources Technology, Gyeongsang National University, \\ Jinju 52725, Republic of Korea \\ ${ }^{2}$ Graduate School of International Agricultural Technology, Seoul National University, Seoul 25354, Republic of Korea \\ ${ }^{3}$ Institutes of Green Bio Science \& Technology, Seoul National University, Seoul 25354, Republic of Korea \\ Correspondence should be addressed to Jin-Yeon Jeong; jinyeon.jeong2@gmail.com
}

Received 31 December 2020; Revised 8 April 2021; Accepted 25 May 2021; Published 4 June 2021

Academic Editor: Luis Patarata

Copyright (c) 2021 Sang-Keun Jin et al. This is an open access article distributed under the Creative Commons Attribution License, which permits unrestricted use, distribution, and reproduction in any medium, provided the original work is properly cited.

\begin{abstract}
In this study, we assessed the antioxidative ability of 23 natural sources in a meat model system at the same addition level (1.0\%). We evaluated the free radical (2,2-diphenyl-1-picrylhydrazyl, DPPH) scavenging ability of natural plant sources and their peroxides, as well as their aldehyde-inhibiting ability in pork patties, over 10 days of cold storage. It was found that blueberries, cherries, onions, black tea, and clove buds (20.6-25.0 mg AA/g) have a higher DPPH scavenging ability than that of other natural sources $(10.80-16.7 \mathrm{mg} \mathrm{AA} / \mathrm{g})(P<0.05)$. Moreover, it was found that peroxides in pork patties are largely inhibited by red wine, lettuce, and red ginseng $(P<0.05)$, whereas aldehydes are significantly inhibited by blueberries, chokeberries (aronia), blackcurrant, clove buds, elderberries, ginger, and cinnamon $(P<0.05)$. These inconsistencies detected in the antioxidative ability of these 23 natural sources indicate that it is important to perform comprehensive and practical assessments of the potential antioxidative ability of natural sources. In addition, it is assumed that the interactions between natural plant sources and meat components affect the inhibition of lipid oxidation in meat and meat products.
\end{abstract}

\section{Introduction}

Meat and meat products comprise various components (e.g., amino acids, fatty acids, vitamins, and minerals) that are considered important nutritional sources in the human diet $[1,2]$. These meat components undergo chemical changes during processing or storage, resulting in changes in their quality and nutritional value [3-5]. For example, lipid oxidation leads to the deterioration of quality and the accumulation of secondary oxidation products, such as aldehydes, alkanes, ketones, and alcohols [6], which directly affect the flavor, texture, color, and protein stability of meat [7]. Therefore, several studies have focused on the effects of these possible toxic lipid oxidation products on human health $[8,9]$. Thus, to delay lipid oxidation in meat products, several synthetic antioxidants, such as butylated hydroxytoluene, butylated hydroxyanisole, tert-butylhydroquinone, and propyl gallate, are extensively used. However, their use is limited because of their toxicity, gastric etiology, and associated food allergies $[10,11]$. Therefore, given the potential toxicity and side effects of synthetic antioxidants, many consumers demand natural antioxidants.

Lipid oxidation can be delayed or inhibited mainly by scavenging free radicals, donating electrons, or chelating metal ions such as $\mathrm{Fe}^{2+}, \mathrm{Fe}^{3+}$, and $\mathrm{Cu}^{2+}$ [12]. It has also been demonstrated that the phenolic compounds, carotenoids, and essential oils present in natural sources have an antioxidative ability [13-17]. Most natural antioxidants are found in plant parts (fruits, leaves, grains, seeds, and roots), agroindustrial byproducts (arils and barks), and their processed products (extracted, grinded, fermented, and dried) [18-20]. Many extensive studies on meat systems have been performed to investigate phytochemicals with an antioxidative ability in various natural sources $[4,12,21,22]$. In addition, several studies have discussed and summarized the mechanism of lipid oxidation and the effects of natural 
antioxidants in meat systems $[4,6,12,20]$. However, no comprehensive assessments have so far been performed on many natural antioxidants derived from different species, plant parts, or processing methods to assess their antioxidative ability under the same conditions. Thus, the aim of this study is to categorize various natural sources according to their antioxidative ability to help select natural antioxidants for practical use in meat and meat products.

\section{Materials and Methods}

2.1. Preparation of Natural Plant Sources. A total of 23 natural plant sources were selected to assess their antioxidative abilities in a meat system on the basis of the results of phytochemicals with antioxidant functions demonstrated previously (Table S1). Raw materials were obtained from different plant parts, such as fruits (noni, apples, chili pepper, and grapes), berries (blackcurrant, blueberries (BB), elderberries, chokeberries (aronia), and cherries), leaves (lettuce and green tea), bulbs (onion and garlic), roots (ginger and ginseng), legumes (soybean), stems with leaves (celery and cinnamon), roots with leaves (radish and thistle), and buds (cloves) (Table 1). Fresh or processed products were purchased from a local market in the Republic of Korea. Before these materials were used, they were dehydrated, milled, or homogenized and finally prepared into a powder, fluid, or puree. To prepare a powder, all natural sources were freeze-dried at $-80^{\circ} \mathrm{C}$ at a pressure of $0.2 \mathrm{~mm}$ $\mathrm{Hg}$ for $24 \mathrm{~h}$ in a vacuum concentrator (MaxiVac, LaboGene, Bjarkesvej, Sweden), milled using a Mixer Mill MM 400 (Retsch, Haan, Germany), and sieved through a mesh (No. 80; $0.18 \mathrm{~mm}$ sieve size). To prepare a puree, an AM-10 ACE Homogenizer (Nihonseiki Kaisha, Ltd., Tokyo, Japan) was used. Soy sauce and Kimchi fluid were used directly without pretreatment. Natural plant sources were classified into three different groups based on their final type before use (powder, fluid, and puree), and their antioxidant abilities (radical scavenging and peroxide- or aldehyde-inhibiting abilities) were compared within the same group.

2.2. Preparation of Pork Patties. Pork leg and fatback were purchased from a local market in Jinju, Republic of Korea. Pork was obtained from five female pigs $(82-85 \mathrm{~kg}$ carcass weight, $48 \mathrm{~h}$ after slaughter), which were first deboned, and then, all subcutaneous fat and excessive connective tissue were removed. Lean meat (semimembranosus, semitendinosus, gluteus medius, and biceps femoris) and fresh fatback pork were minced with a $5 \mathrm{~mm}$ plate using a mincer (GG-22, Hankook Fujee Industries Co., Ltd., Hwaseong, Republic of Korea) and divided into three parts (batches). Then, the minced lean and fresh fatback pork of each batch were premixed individually using an RC-40 mixer (Mainca, Granollers, Spain) with ice and additives but without natural plant sources according to the following formulation: $75 \%$ lean pork, $10 \%$ fatback pork, $10 \%$ ice, and $1.0 \%$ sodium chloride. Then, the premixture was divided into 24 parts, and each part was mixed again with a $1.0 \%$ natural plant source $(n=23)$ or without a natural plant source (control).
Approximately $90 \mathrm{~g}$ of each molded patty (diameter: $90 \mathrm{~mm}$, height: $15 \mathrm{~mm}$ ) was packaged aerobically in a polypropylene bag, and 10 patties per group were prepared and then stored in a cold room at $4^{\circ} \mathrm{C}$. After 1 day and 10 days of storage, five patties from each group were removed from the bags and tested. Notably, the preparation and sampling of the pork patties for the three batches were conducted in a cold room (temperature below $10^{\circ} \mathrm{C}$ ).

\subsection{2, 2-Diphenyl-1-picrylhydrazyl Radical Scavenging Activity.} To evaluate the free radical scavenging ability, 2,2-diphenyl1-picrylhydrazyl (DPPH) radical scavenging activity was determined according to the method described by BrandWilliams et al. [23] with some modifications. Briefly, $1 \mathrm{~g}$ of natural sources was mixed with $1.5 \mathrm{~mL}$ of $99.5 \%$ ethanol. The mixture was then reacted with $0.375 \mathrm{~mL}$ of $0.02 \%(\mathrm{w} / \mathrm{v})$ $\mathrm{DPPH}$ in ethanol for $1 \mathrm{~h}$ in the dark at room temperature, and then, the absorbance of the mixture was measured at $515 \mathrm{~nm}$ using a Gen5 microplate reader (BioTek Instruments, Inc., Winooski, VT, USA). Ascorbic acid (AA) was used as a standard for the calibration curve (from 5 to $50 \mathrm{mg}$ / $\mathrm{mL} A \mathrm{~A}, r=0.998$ ), and the DPPH radical scavenging activity was presented as milligrams of AA per gram.

2.4. Peroxide Value. To measure the peroxide value (POV), lipid was extracted from the samples as per the method described by Folch et al. [24] with some modifications. Briefly, $5 \mathrm{~g}$ of pork patty was homogenized with $20 \mathrm{~mL}$ of a solvent mixture of chloroform and methanol $(2: 1, \mathrm{v} / \mathrm{v})$ and filtered through a Whatman No. 1 filter paper. The filtrates were then separated into two layers using $0.88 \% \mathrm{NaCl}$. After removing the upper layer, the lower layer was evaporated using nitrogen gas. Then, the lipid was mixed with a solvent mixture of chloroform and acetic acid (2:3, v/v) under vigorous shaking, and then, a saturated potassium iodide solution was added. After allowing the mixture to stand in the dark for $5 \mathrm{~min}$, it was mixed with $30 \mathrm{~mL}$ of distilled water, and then, the POV was determined by titrating the iodine liberated from potassium iodide with a standardized $0.01 \mathrm{~N}$ sodium thiosulfate solution. A $1 \%(\mathrm{w} / \mathrm{v})$ starch solution was used as an indicator to determine the titration endpoint. The POV is presented as milliequivalents (mEq) of active oxygen per gram of lipid.

2.5. 2-Thiobarbituric Acid-Reactive Substances. In this study, thiobarbituric acid-reactive substances (TBARS) were evaluated using the method described by Salih et al., [25] with some modifications. Briefly, $5 \mathrm{~g}$ of pork patty was homogenized with $20 \mathrm{~mL}$ of $10 \%$ trichloroacetic acid solution and $100 \mu \mathrm{L}$ of $10 \%$ butylated hydroxyanisole at $3,000 \mathrm{rpm}$ for $20 \mathrm{~s}$. The homogenates were then filtered through a Whatman No. 1 filter paper. Then, $5 \mathrm{~mL}$ of the filtrate was collected twice and incubated with $5 \mathrm{~mL}$ of $0.2 \mathrm{M}$ 2-thiobarbituric acid or with distilled water (the blank for each sample) in the dark at room temperature for $24 \mathrm{~h}$. Then, the absorbance of the reactants was measured at $531 \mathrm{~nm}$ using Gen5 (BioTek Instruments, Inc.). The TBARS values 
TABLE 1: Natural sources used as antioxidants in pork patties.

\begin{tabular}{|c|c|c|c|c|c|c|}
\hline \multirow{2}{*}{ Abbreviations } & \multicolumn{3}{|c|}{ Raw materials } & \multicolumn{3}{|c|}{ Products } \\
\hline & Plant name & Scientific classification & Part of plant & Processing type & Product name & Type before use \\
\hline Noni & Noni & Morinda citrifolia & Fruits & Fresh & Noni & Powder \\
\hline Celery & Celery & Apium graveolens & Stems and leaves & Fresh & Celery & Powder \\
\hline $\mathrm{BC}$ & Blackcurrant & Ribes nigrum & Berries & Fresh & Blackcurrant & Powder \\
\hline $\mathrm{EB}$ & Elderberries & Sambucus latipinna & Berries & Fresh & Elderberries & Powder \\
\hline $\mathrm{BB}$ & Blueberries & Vaccinium corymbosum & Berries & Fresh & Blueberries & Powder \\
\hline Lettuce & Lettuce & Lactuca sativa & Leaves & Fresh & Lettuce & Powder \\
\hline Apple & Apple & Malus pumila & Fruits & Fresh & Apple & Powder \\
\hline Thistle & Thistle & Silybum marianum & Roots and leaves & Fresh & Thistle & Powder \\
\hline Cinnamon & Cinnamon & Cinnamomum verum & Stems and leaves & Fresh & Cinnamon & Powder \\
\hline BT & Green tea & Camellia sinensis & Leaves & Fermented & Black tea & Powder \\
\hline Ginger & Ginger & Zingiber officinale & Roots & Fresh & Ginger & Powder \\
\hline $\mathrm{CP}$ & Chili pepper & Capsicum annuum & Fruits & Fresh & Chili pepper & Powder \\
\hline Aronia & Aronia & Aronia melanocarpa & Berries & Fresh & Aronia & Powder \\
\hline Onion & Onion & Allium сера & Bulb & Fresh & Onion & Powder \\
\hline Clove & Clove & Syzygium aromaticum & Bud & Fresh & Clove & Powder \\
\hline Garlic & Garlic & Allium sativum & Bulb & Fresh & Garlic & Powder \\
\hline SS & Soybean & Glycine $\max$ & Legumes & Fermented & Soy sauce & Fluid \\
\hline Kimchi & Radish & Raphanus raphanistrum & Roots and leaves & Fermented & Kimchi & Fluid \\
\hline RW & Grape & Vitis vinifera & Fruits & Fermented & Red wine & Fluid \\
\hline $\mathrm{CB}$ & Cherry & Prunus avium & Berries & Fresh & Cherry berry & Puree \\
\hline RG & Ginseng & Panax ginseng & Roots & Fermented & Red ginseng & Puree \\
\hline SP & Soybean & Glycine $\max$ & Legumes & Fermented & Soybean paste & Puree \\
\hline RCP & Chili pepper & Capsicum annuum & Fruits & Fermented & Red chili paste & Puree \\
\hline
\end{tabular}

were calculated using the standard curve of 1, 1, 3, 3-tetraethoxypropane and presented as milligrams of malondialdehyde (MDA)/kilogram of sample.

2.6. Statistical Analysis. All statistical analyses were performed using SAS software (ver. 9.4; SAS Institute Inc., Cary, NC, USA). Data collected from 24 groups of pork patties from the three batches were presented as means with standard error. Changes in TBARS ( $\triangle$ TBARS) and POV $(\triangle \mathrm{POV})$ over 10 days of cold storage were compared to those in the control group using a $t$-test. Data on the DPPH radical scavenging ability were used for hierarchical cluster analysis (HCA), and the 23 natural plant sources were grouped into clusters according to the Euclidean distance and similarity index ranging from 0 (higher similarity) to 1.63 (lower similarity). Principal component analysis (PCA) was performed to set a new space defined by the principal components (PCs) using the results of DPPH, POV, and TBARS. Notably, PCA was performed on the basis of the correlation matrix, and the first two PCs (PC1 and PC2) explained 77.44\% (PC1: $65.72 \%$ and PC2: 11.72\%) of the total variance.

\section{Results}

3.1. DPPH Radical Scavenging Abilities of Natural Sources. The results of the DPPH radical scavenging ability assays and HCA are shown in Figure 1. Out of all the puree type plant sources, $\mathrm{CB}$ had the highest DPPH radical scavenging ability, at over $20 \mathrm{mg} \mathrm{AA} / \mathrm{g}$. The other puree type sources (RG, SP, and RCP) showed a similar DPPH radical scavenging ability with each other (10.80-10.97 mg AA/g) and clustered separately from CB. Among the fluid type sources, kimchi had higher DPPH radical scavenging ability than SS and RW. Among the 16 powder type sources, clove, BT, onion, and $\mathrm{BB}$ all had a DPPH radical scavenging ability of over $20 \mathrm{mg}$ $\mathrm{AA} / \mathrm{g}$, whereas garlic had the lowest $\mathrm{DPPH}$ radical scavenging ability (10.88 mg AA/g). HCA showed that BB, onion, $\mathrm{BT}$, and clove clustered together and were separate from the other powder type sources.

3.2. Changes in the POV and TBARS of Pork Patties over 10 days of Cold Storage. Increased POV and TBARS were observed in all pork patties after 10 days of cold storage. These values were compared to those of CON (no natural source added) to evaluate the antioxidative effect of natural sources in pork patties (Table 2 and Figure 2). After cold storage, the POV of pork patties were found to range after storage from 0.85 to $2.32 \mathrm{mEqO}_{2} / \mathrm{g}$, resulting in a difference of $0.37-1.84 \mathrm{mEqO}_{2} / \mathrm{g}$ between the values obtained from the initial and the final storage. Among the natural plant sources that were prepared as a powder, lettuce, apple, cinnamon, $\mathrm{BT}$, ginger, $\mathrm{CP}$, and aronia were found to be significantly different $(P<0.05)$ from CON. However, only lettuce showed a lower POV value than that of $C O N$, while the others had higher POV than that of CON. For the other types of natural plant sources, RW (fluid) and RG (puree) had significantly lower $(P<0.05)$ POV than that of CON.

Similarly, increased TBARS values were observed in pork patties following 10 days of cold storage. TBARS values ranging from 0.22 to $1.11 \mathrm{mg} \mathrm{MDA} / \mathrm{kg}$ were observed in pork patties treated with powder type sources at 10 days of cold storage. These TBARS values exhibited differences between the initial and the final storage timepoint, ranging from 0.03 to $0.93 \mathrm{mg} \mathrm{MDA} / \mathrm{kg}$. Among the powder type 

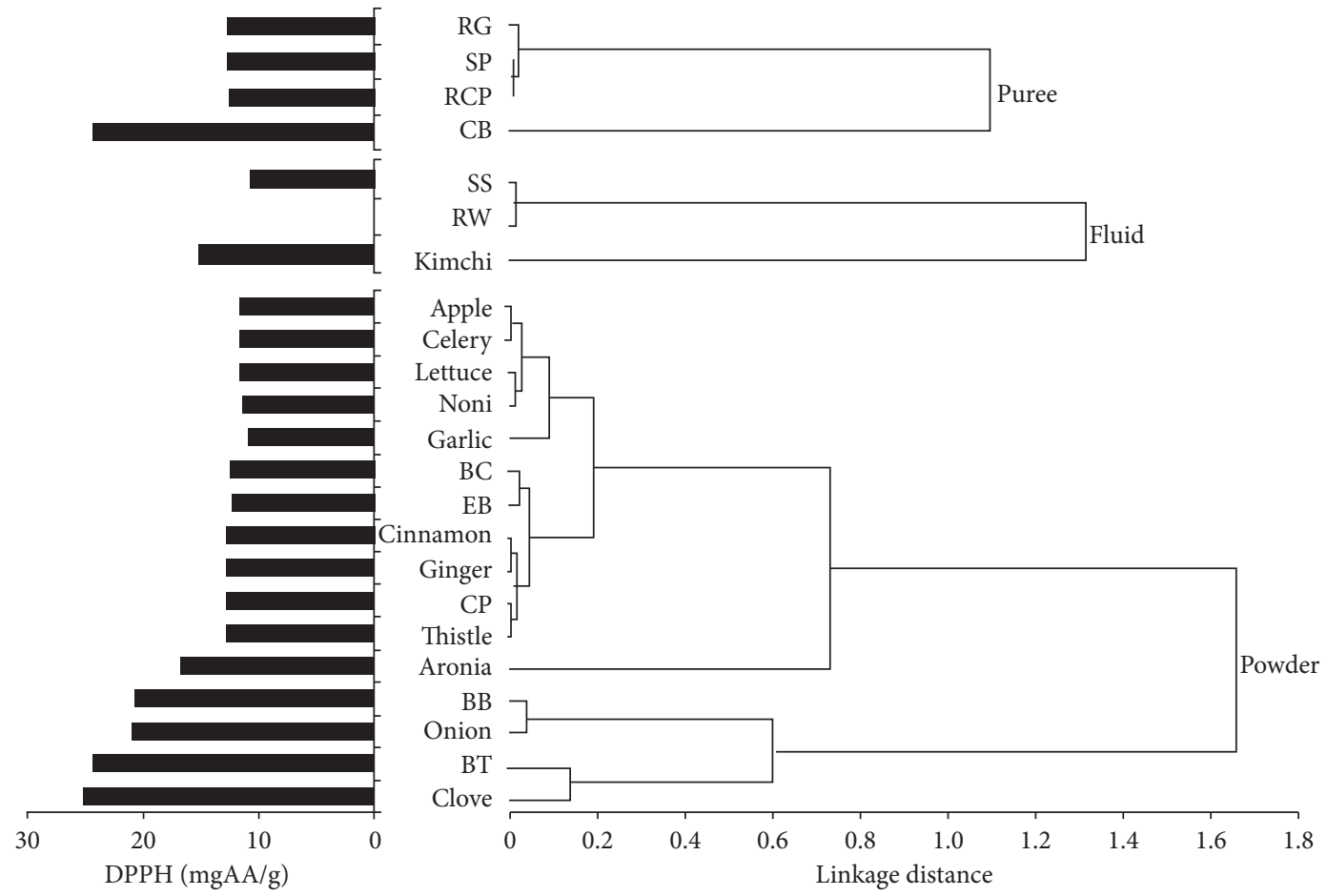

FIGURE 1: Dendrogram for variables from the hierarchical cluster analysis and 2, 2-diphenyl-1-picrylhydrazyl (DPPH) radical scavenging ability of natural plant sources. SS, soy sauce; RW, red wine; RCP, red chili paste; SP, soybean paste; RG, red ginseng; BC, blackcurrant; EB, elderberries; $\mathrm{CP}$, chili pepper; $\mathrm{BB}$, blueberries; $\mathrm{CB}$, cherry berry; $\mathrm{BT}$, black tea.

TABle 2: Antioxidant abilities of natural sources in pork patties after 10 days of cold storage.

\begin{tabular}{|c|c|c|c|c|c|c|}
\hline \multicolumn{3}{|c|}{ Treatments $^{(1)}$} & \multicolumn{4}{|c|}{ Measurements $^{(2)}$} \\
\hline Type & Full name & Abbreviation & $\mathrm{POV}\left(\mathrm{meq} \mathrm{O}_{2} / \mathrm{g}\right.$ ) & $\triangle \mathrm{POV}$ & TBARS (mg MDA/kg) & $\triangle \mathrm{TBARS}$ \\
\hline \multirow{17}{*}{ Powder } & Control & $\mathrm{CON}$ & $1.64 \pm 0.15$ & 1.16 & $0.87 \pm 0.15$ & 0.69 \\
\hline & Noni & Noni & $1.62 \pm 0.15$ & 1.14 & $0.71 \pm 0.03$ & 0.53 \\
\hline & Celery & Celery & $1.50 \pm 0.19$ & 1.02 & $0.64 \pm 0.07$ & 0.45 \\
\hline & Blackcurrant & $\mathrm{BC}$ & $1.49 \pm 0.16$ & 1.01 & $0.31 \pm 0.02^{* *}$ & 0.12 \\
\hline & Elderberries & $\mathrm{EB}$ & $1.80 \pm 0.17$ & 1.32 & $0.42 \pm 0.01^{*}$ & 0.24 \\
\hline & Blueberries & $\mathrm{BB}$ & $1.63 \pm 0.14$ & 1.15 & $0.22 \pm 0.01^{* *}$ & 0.03 \\
\hline & Lettuce & Lettuce & $0.85 \pm 0.17^{*}$ & 0.37 & $0.69 \pm 0.07$ & 0.50 \\
\hline & Apple & Apple & $2.32 \pm 0.02^{*}$ & 1.84 & $0.55 \pm 0.07$ & 0.36 \\
\hline & Thistle & Thistle & $1.55 \pm 0.17$ & 1.07 & $0.77 \pm 0.08$ & 0.58 \\
\hline & Cinnamon & Cinnamon & $2.29 \pm 0.03^{*}$ & 1.81 & $0.49 \pm 0.03^{*}$ & 0.31 \\
\hline & Black tea & BT & $2.31 \pm 0.01^{*}$ & 1.83 & $0.57 \pm 0.01$ & 0.38 \\
\hline & Ginger & Ginger & $2.30 \pm 0.03^{*}$ & 1.82 & $0.45 \pm 0.04^{*}$ & 0.27 \\
\hline & Chili pepper & $\mathrm{CP}$ & $2.30 \pm 0.03^{*}$ & 1.82 & $0.57 \pm 0.06$ & 0.39 \\
\hline & Aronia & Aronia & $2.30 \pm 0.03^{*}$ & 1.82 & $0.27 \pm 0.01^{* *}$ & 0.09 \\
\hline & Onion & Onion & $2.08 \pm 0.08$ & 1.60 & $0.90 \pm 0.06$ & 0.72 \\
\hline & Clove & Clove & $1.83 \pm 0.12$ & 1.35 & $0.38 \pm 0.03^{*}$ & 0.19 \\
\hline & Garlic & Garlic & $1.78 \pm 0.15$ & 1.30 & $1.11 \pm 0.08$ & 0.93 \\
\hline \multirow{3}{*}{ Fluid } & Soy sauce & SS & $1.68 \pm 0.11$ & 1.20 & $0.88 \pm 0.08$ & 0.70 \\
\hline & Kimchi & Kimchi & $1.85 \pm 0.20$ & 1.37 & $1.10 \pm 0.21$ & 0.91 \\
\hline & Red wine & RW & $0.92 \pm 0.07^{*}$ & 0.44 & $0.71 \pm 0.08$ & 0.52 \\
\hline \multirow{4}{*}{ Puree } & Cherry berry & $\mathrm{CB}$ & $1.87 \pm 0.19$ & 1.39 & $1.17 \pm 0.17$ & 0.98 \\
\hline & Red ginseng & RG & $0.99 \pm 0.08^{*}$ & 0.51 & $0.69 \pm 0.09$ & 0.51 \\
\hline & Soybean paste & $\mathrm{SB}$ & $1.46 \pm 0.10$ & 0.98 & $1.11 \pm 0.07$ & 0.92 \\
\hline & Red chili paste & RCP & $1.60 \pm 0.21$ & 1.12 & $0.76 \pm 0.06$ & 0.57 \\
\hline
\end{tabular}

Data are means \pm SE. ${ }^{(1)} \mathrm{CON}$, no addition; all treatments except for CON were treated $1.0 \%$ of natural sources. ${ }^{(2)}$ TBARS, thiobarbituric acid-reactive substances; $\triangle$ TBARS, difference between initial and final values of TBARS; POV, peroxide value; $\triangle \mathrm{POV}$, difference between initial and final values of POV. ${ }^{*}$ Significant difference $\left({ }^{*} P<0.05 ;{ }^{*} P<0.01\right)$ when compared to CON. 


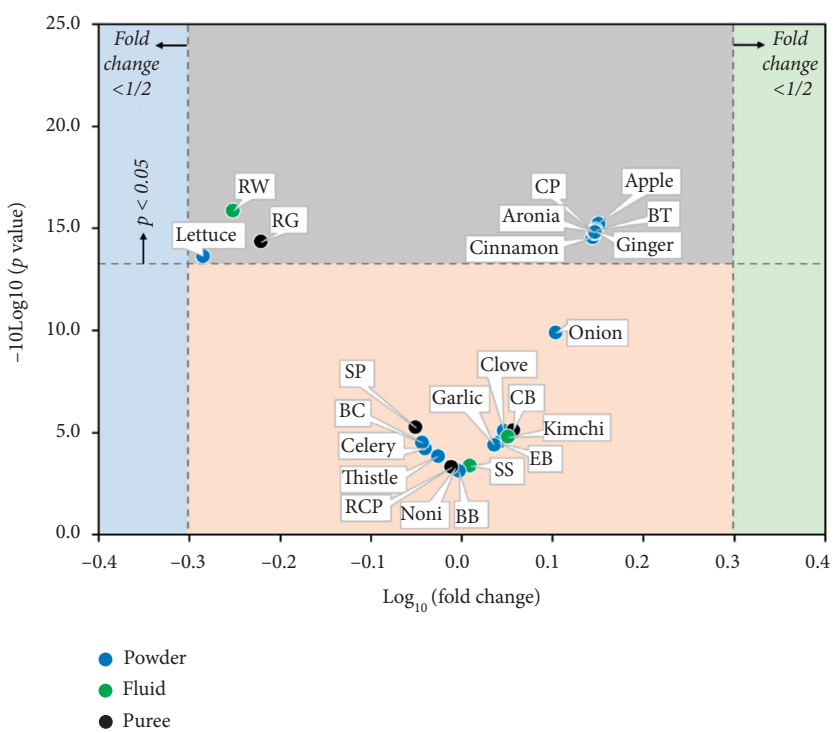

(a)

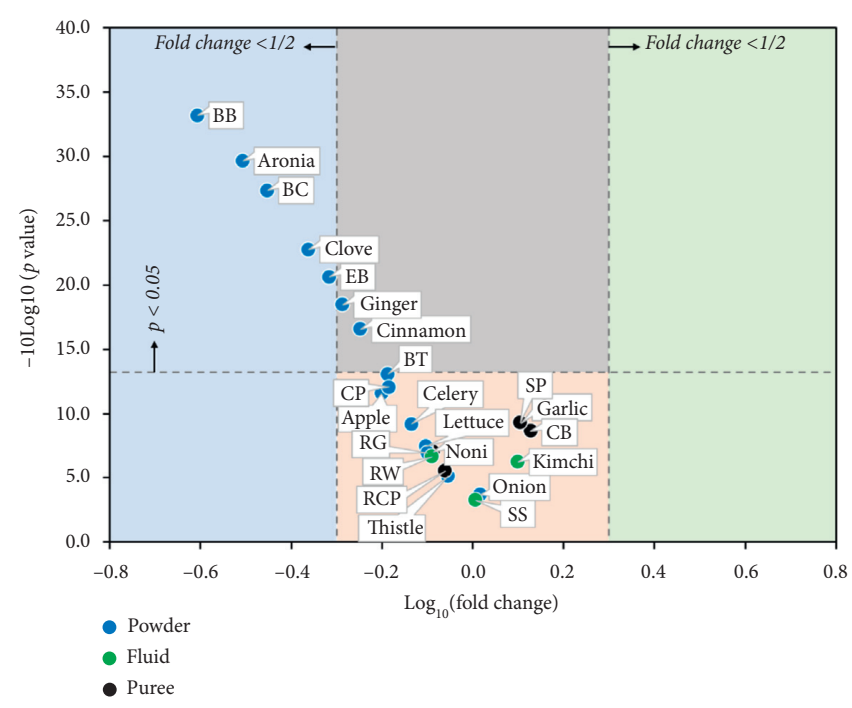

(b)

FIgURE 2: (a) Volcano plots for peroxide value (POV) and (b) 2-thiobarbituric acid-reactive substances (TBARS) of pork patties. SS, soy sauce; RW, red wine; RCP, red chili paste; SP, soybean paste; RG, red ginseng; BC, blackcurrant; EB, elderberries; CP, chili pepper; $\mathrm{BB}$, blueberries; CB, cherry berry; BT, black tea.

natural sources, $\mathrm{BC}, \mathrm{EB}, \mathrm{BB}$, aronia, ginger, cinnamon, and clove showed significantly lower TBARS values than those of CON $(P<0.05)$. In addition, these natural sources, except for ginger and cinnamon, showed a $\triangle T B A R S$ value that was less than half of that of CON (Figure 2(b)). In contrast, none of natural sources prepared in fluid or puree form exhibited a TBARS value significantly different from that of CON $(P>0.05)$. Higher TBARS values than those in CON were observed in onions, garlic, SS, CB, SB, and kimchi, but these differences were not significant $(P>0.05)$.

3.3. Principal Component Analysis. Figure 3 shows the results of the PCA conducted based on the DPPH radical scavenging ability, POV, and TBARS values. For the powder type sources, $\mathrm{CP}, \mathrm{BT}$, apple, ginger, aronia, and cinnamon clustered together, while the other powder type natural plant sources were separate from this group. Notably, lettuce trended differently than the other powder types and was grouped with RW, a fluid type source. For the puree type sources, the four natural sources, $\mathrm{CB}, \mathrm{RG}, \mathrm{SB}$, and RCP, tended differently from each other. Among these, SP tended similarly to some of the powder type sources such as clove, $\mathrm{BB}$, and $\mathrm{EB}$, whereas the others did not cluster with any other natural sources, regardless of preparation type. Similar to the puree type sources, the three fluid types (SS, RW, and kimchi) tended distinctly from each other in PCA.

\section{Discussion}

During the processing of meat and meat products, free radicals from reactive oxygen species and prooxidants resulting from thermal treatment, ultraviolet radiation, and redox reactions initiate the oxidation of unsaturated fatty acids through the loss of a hydrogen radical [4]. Natural

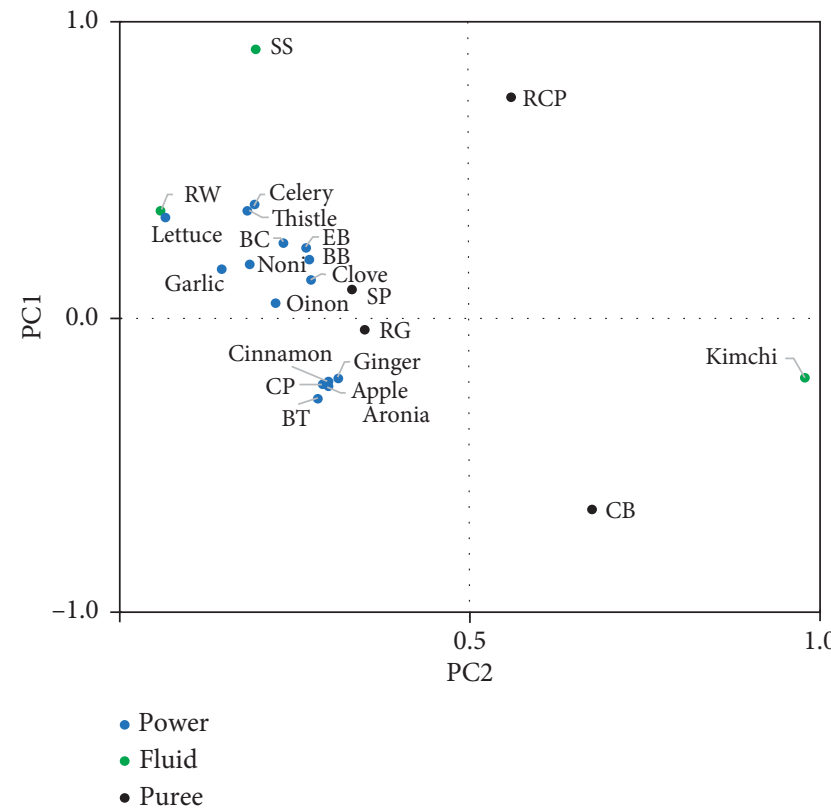

FIGURe 3: Principal component analysis (PCA) plot. PCA loadings plot for different variables on the two first principal components (PC1 and PC2). SS, soy sauce; RW, red wine; RCP, red chili paste; $\mathrm{SP}$, soybean paste; RG, red ginseng; $\mathrm{BC}$, blackcurrant; $\mathrm{EB}$, elderberries; $\mathrm{CP}$, chili pepper; $\mathrm{BB}$, blueberries; $\mathrm{CB}$, cherry berry; $\mathrm{BT}$, black tea.

antioxidants generally delay lipid oxidation by donating a hydrogen atom or binding metal ions [25]. In addition, polyphenols such as phenolic acids and flavonoids [4], which are considered antioxidants and are present in various natural sources, can scavenge free radicals, resulting in the inhibition of lipid oxidation [4]. Notably, in this study, BB, 
$\mathrm{CB}$, onions, BT (fermented green tea), and clove buds showed a higher radical scavenging ability than that of the other sources. Several studies have also demonstrated that berries, including $\mathrm{BB}$ and $\mathrm{CB}$, clove buds, and $\mathrm{BT}$ contain large amounts of flavonoids and phenolic acids and that onions contain flavonols (particularly quercetin) [26-28]. However, although these natural sources exhibit a strong free radical scavenging ability, none of them reduced the level of peroxides in pork patties when compared to CON. Moreover, it was found that BT increased the POV of pork patties after 10 days of storage and that BT, CP, apples, aronia, ginger, and cinnamon generally increased the POV of pork patties. Notably, the highest peroxide scavenging ability was observed in RW, RG, and lettuce.

Lipid oxidation produces secondary oxidation products in meat and meat products, such as aldehydes, ketones, alcohols, and carbonyl compounds [4]. These aldehydes, which are produced by the lipid peroxidation of polyunsaturated fatty acids, are considered key compounds, which is why mainly MDA is quantified to evaluate lipid oxidation [29]. In this study, it was found that $\mathrm{BB}$, aronia, $\mathrm{BC}$, cloves, and $\mathrm{EB}$ strongly (over twice the level of $\mathrm{CON}$ ) inhibit MDA formation. Therefore, given the findings from both the POV and the TBARS assays, it was concluded that the primary and secondary products produced by lipid oxidation are differently affected by natural sources. This observation seems to be the result of the combination effect of various antioxidants in individual natural sources. Most natural sources contain polyphenols, which are major antioxidants in plants; however, individual sources have different amounts of polyphenols and other antioxidant substances. Generally, AA and tocopherol are found in berries and fruits as well as their products (red wine), whereas polysaccharides and $\beta$-carotene are found in ginseng (or red ginseng) and lettuce, respectively $[20,30,31]$. In addition, many biopeptides with an antioxidative ability are produced in meat and meat products, which can inhibit lipid oxidation [32]. It is possible that these biopeptides may rather inhibit the antioxidative function of natural sources in meat and meat products. However, no detailed studies have yet been performed to investigate this phenomenon.

As expected, powder type sources showed a higher antioxidant ability than fluid or puree types, as lower TBARS values were found in $\mathrm{BC}, \mathrm{EB}, \mathrm{BB}$, cinnamon, ginger, aronia, and cloves than in any fluid or puree type sources. However, ginger, aronia, and cinnamon were not effective at reducing POV. Thus, the potential antioxidative ability of raw sources depends on both the free radical scavenging ability as well as the preparation method; however, the practical effects on antioxidant in meat and meat products are determined by evaluation of inhibiting primary or secondary products of lipid oxidation. Accordingly, free radical (DPPH) scavenging abilities and peroxide- or aldehyde-inhibiting abilities (POV, TBARS) of raw natural sources allow them to cluster into several groups with similar antioxidants. In particular, lettuce, RW, and RG are expected to strongly inhibit peroxides, whereas $\mathrm{BC}, \mathrm{BB}$, cloves, aronia, ginger, cinnamon, $\mathrm{CP}, \mathrm{BT}$, and apples are expected to strongly inhibit aldehydes in meat and meat products. Although the remaining natural sources, that is, onions, kimchi, $\mathrm{CB}$, garlic, and SS, did not show a prominent antioxidative ability, their potential antioxidative ability cannot be assessed. All natural sources were tested in pork patties at the same addition level without considering the individual antioxidative ability, which depends on the species, parts used, and pretreatment methods, as well as the cultivation conditions, postharvest handling, and processing methods for each source $[4,27,33]$. Therefore, consideration of each individual source's peroxide- and aldehyde-inhibiting ability is essential for practical applications to meat and meat products. More studies are needed to investigate the inconsistent trends displayed by different plant sources in their ability to scavenge free radicals and to inhibit primary and secondary lipid oxidation products. Additionally, further investigation of potential interactions or combination effects between antioxidant substances and meat biopeptides are needed.

\section{Conclusion}

In this study, it was found that the 23 investigated natural sources, at the same addition level, displayed varying ability to scavenging free radicals or inhibit primary and secondary lipid oxidation products. Further studies are needed before natural sources can be applied to the production of meat and meat products.

\section{Abbreviations}

DPPH: 2,2-Diphenyl-1-picrylhydrazyl

POV: Peroxide value

AA: Ascorbic acid

TBARS: 2-Thiobarbituric acid-reactive substances

MDA: Malondialdehyde

BB: Blueberries

CB: Cherry berry

BT: $\quad$ Black tea

SS: $\quad$ Soy sauce

RW: $\quad$ Red wine

RCP: $\quad$ Red chili paste

SP: $\quad$ Soybean paste

RG: $\quad$ Red ginseng

BC: Blackcurrant

EB: $\quad$ Elderberries

CP: Chili pepper.

\section{Data Availability}

The data used to support the findings of this study are available from the corresponding author upon request.

\section{Conflicts of Interest}

The authors declare that they have no conflicts of interest.

\section{Authors' Contributions}

Sang-Keun Jin and Gap-Don Kim contributed equally to this work. 


\section{Acknowledgments}

This work was supported by the 2020 Post-Doc Development Program of Gyeongsang National University and by Korea Institute of Planning and Evaluation for Technology in Food, Agriculture, Forestry and Fisheries (IPET) through High Value-added Food Technology Development Program, funded by Ministry of Agriculture, Food and Rural Affairs (MAFRA) (118039-03-1-HD020).

\section{Supplementary Materials}

Table S1. Natural sources used for antioxidant in meat and meat products. (Supplementary Materials)

\section{References}

[1] M. A. Binnie, K. Barlow, V. Johnson, and C. Harrison, "Red meats: time for a paradigm shift in dietary advice," Meat Science, vol. 98, no. 3, pp. 445-451, 2014.

[2] R. A. Lawrie and D. Ledward, Chemical and Biochemical Constitution of Muscle. Lawrie's Meat Science, Woodhead Publishing, Sawston, Cambridge, 7th edition, 2006.

[3] S. K. Devatkal, P. Thorat, and M. Manjunatha, "Effect of vacuum packaging and pomegranate peel extract on quality aspects of ground goat meat and nuggets," Journal of Food Science and Technology, vol. 51, no. 10, pp. 2685-2691, 2014.

[4] Y. Kumar, D. N. Yadav, T. Ahmad, and K. Narsaiah, "Recent trends in the use of natural antioxidants for meat and meat products," Comprehensive Reviews in Food Science and Food Safety, vol. 14, no. 6, pp. 796-812, 2015.

[5] R. A. Lawrie, "Chemical changes in meat due to processing-a review," Journal of the Science of Food and Agriculture, vol. 19, no. 5, pp. 233-240, 1968.

[6] J. M. Lorenzo, M. Pateiro, R. Domínguez et al., "Berries extracts as natural antioxidants in meat products: a review," Food Research International, vol. 106, pp. 1095-1104, 2018.

[7] B. Min and D. U. Ahn, "Mechanism of lipid peroxidation in meat and meat products-a review," Food Science and Biotechnology, vol. 14, pp. 152-163, 2005.

[8] S. Kubow, "Routes of formation and toxic consequences of lipid oxidation products in foods," Free Radical Biology and Medicine, vol. 12, no. 1, pp. 63-81, 1992.

[9] G. Duthie, F. Campbell, C. Bestwick, S. Stephen, and W. Russell, "Antioxidant effectiveness of vegetable powders on the lipid and protein oxidative stability of cooked Turkey meat patties: implications for health," Nutrients, vol. 5, no. 4, pp. 1241-1252, 2013.

[10] C. M. Hasler, "The changing face of functional foods," Journal of the American College of Nutrition, vol. 19, no. 5, pp. 499S-506S, 2000.

[11] A. Moure, J. M. Cruz, D. Franco et al., "Natural antioxidants from residual sources," Food Chemistry, vol. 72, no. 2, pp. 145-171, 2001.

[12] L. C. M. Cunha, M. L. G. Monteiro, J. M. Lorenzo et al., "Natural antioxidants in processing and storage stability of sheep and goat meat products," Food Research International, vol. 111, pp. 379-390, 2018.

[13] P. E. S. Munekata, D. Franco, M. A. Trindade, and J. M. Lorenzo, "Characterization of phenolic composition in chestnut leaves and beer residue by LC-DAD-ESI-MS," LWTFood Science and Technology, vol. 68, pp. 52-58, 2016.
[14] M. Muchuweti, E. Kativu, C. H. Mupure, C. Chidewe, A. R. Ndhlala, and M. A. N. Benhura, "Phenolic composition and antioxidant properties of some spices," American Journal of Food Technology, vol. 2, no. 5, pp. 414-420, 2007.

[15] N. Geldof and N. J. Engeseth, "Antioxidant capacity of honeys from various floral sources based on the determination of oxygen radical absorbance capacity and inhibition of in vitro lipoprotein oxidation in human serum samples," Journal of Agricultural and Food Chemistry, vol. 50, pp. 3050-3055, 2002.

[16] A. Wojdylo, J. Oszmianski, and R. Czemerys, "Antioxidant activity and phenolic compounds in 32 selected herbs," Food Chemistry, vol. 105, no. 3, pp. 940-949, 2007.

[17] A. Delgado, S. Al-Hamimi, M. F. Ramadan et al., "Contribution of tocols to food sensorial properties stability and overall quality," Journal of Food Quality, vol. 2020, Article ID 8885865, 8 pages, 2020.

[18] R. Agregán, P. E. S. Munekata, D. Franco, D. Dominguez, J. Carballo, and J. M. Lorenzo, "Proximate composition phenolic content and in vitro antioxidant activity of aqueous extracts of the seaweeds Ascophyllum nodosum Bifurcaria bifurcata and Fucus vesiculosus. Effect of addition of the extracts on the oxidative stability of canola oil under accelerated storage conditions," Food Research International, vol. 99, pp. 986-994, 2007.

[19] D. Hygreeva, M. C. Pandey, and K. Radhakrishna, "Potential applications of plant based derivatives as fat replacers antioxidants and antimicrobials in fresh and processed meat products," Meat Science, vol. 98, no. 1, pp. 47-57, 2014.

[20] M. Pateiro, F. J. Barba, R. Domínguez et al., "Essential oils as natural additives to prevent oxidation reactions in meat and meat products: a review," Food Research International, vol. 113, pp. 156-166, 2018.

[21] J. S. Ribeiro, M. J. M. C. Santos, L. K. R. Silva et al., "Natural antioxidants used in meat products: a brief review," Meat Science, vol. 148, pp. 181-188, 2019.

[22] P. E. S. Munekata, G. Rocchetti, M. Pateiro, L. Lucini, R. Domínguez, and J. M. Lorenzo, "Addition of plant extracts to meat and meat products to extend shelf-life and healthpromoting attributes: an overview," Current Opinion in Food Science, vol. 31, pp. 81-87, 2020.

[23] W. Brand-Williams, M. E. Cuvelier, and C. Berset, "Use of a free radical method to evaluate antioxidant activity," $L W T$ Food Science and Technology, vol. 28, no. 1, pp. 25-30, 1995.

[24] J. Folch, M. Lees, and G. H. Sloane-Stanley, "A simple method for the isolation and purification of total lipids from animal tissues," Journal of Biological Chemistry, vol. 226, pp. 497-509, 2015.

[25] A. M. Salih, D. M. Smith, J. F. Price, and L. E. Dawson, "Modified extraction 2-thiobarbituric acid method for measuring lipid oxidation in poultry," Poultry Science, vol. 66, no. 9, pp. 1483-1488, 1987.

[26] T. Masuda, Y. Inaba, and Y. Takeda, "Antioxidant mechanism of carnosic acid: structural identification of two oxidation products," Journal of Agricultural and Food Chemistry, vol. 49, no. 11, pp. 5560-5565, 2001.

[27] A. N. Panche, A. D. Diwan, and S. R. Chandra, "Flavonoids: an overview," Journal of Nutritional Science, vol. 5, no. e47, pp. e47-15, 2016.

[28] R. R. Cardoso, R. O. Neto, C. T. Dos Santos D’Almeida et al., "Kombuchas from green and black teas have different phenolic profile which impacts their antioxidant capacities antibacterial and antiproliferative activities," Food Research International, vol. 128, Article ID 108782, 2020. 
[29] C. Shi, J. Cui, X. Yin, Y. Luo, and Z. Zhou, "Grape seed and clove bud extracts as natural antioxidants in silver carp (Hypophthalmichthys molitrix) fillets during chilled storage: effect on lipid and protein oxidation," Food Control, vol. 40, pp. 134-139, 2014.

[30] C. Guyon, A. Meynier, A. Meynier, and M. De Lamballerie, "Protein and lipid oxidation in meat: a review with emphasis on high-pressure treatments," Trends in Food Science \& Technology, vol. 50, pp. 131-143, 2016.

[31] F. Chen and G. Huang, "Antioxidant activity of polysaccharides from different sources of ginseng," International Journal of Biological Macromolecules, vol. 125, pp. 906-908, 2019.

[32] M. J. Kim, Y. Moon, J. C. Tou, B. Mou, and N. L. Waterland, "Nutritional value bioactive compounds and health benefits of lettuce (Lactuca sativa L.)," Journal of Food Composition and Analysis, vol. 49, pp. 19-34, 2016.

[33] C. C. Udenigwe and A. Howard, "Meat proteome as source of functional biopeptides," Food Research International, vol. 54, no. 1, pp. 1021-1032, 2013. 